\title{
SENSIBILIDADE MORAL DE LICENCIANDOS EM QUÍMICA: QUESTÕES SOCIOCIENTÍFICAS EM FOCO
}

\author{
Pre-service chemistry teachers' ${ }^{\prime}$ moral sensitivity: socioscientific issues in focus
}

Sensibilidad moral de licenciados en química: cuestiones sociocientíficas en foco

\author{
Guilherme Balestiero da Silva* \\ Salete Linhares Queiroz*
}

\begin{abstract}
Resumo
Com base nos princípios da abordagem ciência-tecnologia-sociedade (CTS), emerge da literatura a importância do emprego de questões sociocientíficas (QSC) no ensino de ciências. Estas, de relevância social e natureza controversa, envolvem múltiplos pontos de vista, de modo que o seu tratamento incorpora conteúdos próprios do espaço formal de ensino e também oferece aos estudantes a oportunidade de considerar aspectos sociais, econômicos, éticos e morais. Neste trabalho, temos como objetivo investigar a sensibilidade moral de licenciandos em química, com base nos aspectos morais evidenciados em suas respostas a esse tipo de questão, relacionadas à leitura de um caso extraído de um texto quadrinizado. Para tanto, tomamos como referencial teórico o Modelo dos Quatro Componentes. Concluímos que, a princípio, os futuros professores não apresentaram elevada sensibilidade moral, porém, a ação levada a cabo em sala de aula contribuiu positivamente para o seu desenvolvimento. Salientamos ainda a adequação e a relevância do Modelo dos Quatro Componentes para estudos envolvendo o desenvolvimento moral de licenciandos.
\end{abstract}

PALAVRAS-CHAVE: Ensino de Química. Formação Inicial de Professores. História em Quadrinhos

\begin{abstract}
Based on the principles of the science-technology-society (STS) approach, the importance of using socio-scientific issues (SSI) in science teaching emerges from the literature. These issues are of social relevance and controversial in nature and involve multiple points of view, so much so that their treatment incorporates content suitable for the formal educational environment and also offers students the opportunity to consider social, economic, ethical and moral aspects. In this study, we aim to investigate the pre-service chemistry teachers' moral sensitivity based on the moral aspects seen in their responses to this type of issue, related to the reading of a case extracted from a comic book text. To do this, we take the Four Component Model as a theoretical reference. We conclude that, in the beginning, the future teachers did not present a high moral sensitivity, but the actions carried out in the classroom contributed positively to their development. We also emphasize the adequacy and relevance of the Four Component Model for studies involving the undergraduates' moral development.
\end{abstract}

KEYWORDS: Chemistry Education. Pre-service Teacher Education. Comic Book Text

\footnotetext{
* Mestre em Ensino de Ciências. Pesquisador do Grupo de Pesquisa em Ensino de Química (GPEQsc /USP). E-mail: guilherme.balestiero@gmail.com.

* Doutora em Química e Pós-Doutora em Educação. Professora livre-docente do Instituto de Química de São Carlos (USP). Coordenadora do Grupo de Pesquisa em Ensino de Química (GPEQsc /USP). E-mail: salete@iqsc.usp.br.
} 


\section{Resumen}

Con base en los principios del abordaje de ciencia-tecnología-sociedad (CTS), emerge de la literatura la importancia de la utilización de cuestiones sociocientíficas (QSC) en la enseñanza de las ciencias. Estas, de relevancia social y naturaleza polémica, envuelven múltiples puntos de vista, de modo que su tratamiento incorpora contenidos propios del espacio formal de la enseñanza y también ofrece a los estudiantes la oportunidad de considerar los aspectos sociales, económicos, éticos y morales. En este trabajo tenemos como objetivo investigar la sensibilidad moral de licenciados en química fundamentados en los aspectos morales evidenciados en las respuestas de ellos a este tipo de cuestionamientos, relacionadas a la lectura de un caso extraído de un libro de historietas. Para esto, tomamos como referencia teórica el Modelo de los Cuatro Componentes. Concluimos que, inicialmente, los futuros profesores no mostraron elevada sensibilidad moral, sin embargo la acción llevada a cabo en sala de aula contribuyó positivamente para su desarrollo. Resaltamos además la adecuación e importancia del Modelo de los Cuatro Componentes para estudios relacionados con el desarrollo moral de licenciados.

PALABRAS CLAVE: Enseñanza de la Química. Formación Inicial de Profesores. Libro de Historieta

\section{INTRODUÇÃO}

Sabemos, por meio de diferentes estudos e investigações (CACHAPUZ et al., 2008; AULER, 2011; PEDRETTI; NAZIR, 2011), que a ciência se torna mais significativa para os estudantes quando inserida em um contexto que revela como esta se relaciona com tecnologia, e como, por sua vez, a tecnologia é empregada pela sociedade. Nessa perspectiva, um currículo que permita que os estudantes lidem com dilemas sociais vai ao encontro dos propósitos da abordagem ciência-tecnologia-sociedade (CTS), cujos princípios referem-se à racionalidade científica, ao desenvolvimento tecnológico e à participação social (STRIEDER; KAWAMURA, 2017).

Assumindo, portanto, os ideais de um currículo CTS, Zeidler et al. (2005) apresentam considerações a respeito do emprego de questões sociocientíficas (QSC) em salas de aulas de ciência, as quais, de acordo com os autores, permitem ao educador extrapolar os objetivos primários dessa corrente CTS, cuja origem remete à década de 1980 (ROEHRIG; CAMARGO, 2014).

Segundo Karisan e Zeidler (2017), a inserção de QSC no ensino de ciências vai ao encontro da premissa da educação científica das últimas três décadas, a alfabetização científica, que por sua vez é um constructo multidimensional e complexo. Para Sadler (2011), reiterado por Karisan e Zeidler (2017), um indivíduo cientificamente alfabetizado deve ser capaz de negociar e tomar decisões diante de situações do cotidiano que envolvam o conteúdo científico. Ademais, deve ser capaz de compreender os impactos da ciência e da tecnologia no dia a dia, além de ler e entender os tópicos essenciais veiculados pela mídia, refletindo criticamente sobre as informações.

Sadler (2004) define as QSC como dilemas sociais com conceitos, procedimentos ou tecnologias associadas com a ciência; é o caso, por exemplo, de alterações climáticas, como o aquecimento global, terapias genéticas e polêmicas médicas como a questão da vacinação. Controversas por natureza, elas consistem geralmente em problemas mal estruturados, isto é, que não apresentam objetivamente a questão principal a ser resolvida, ficando a cargo dos indivíduos a tarefa de identificá-la. Estas podem ser consideradas por 
uma variedade de perspectivas, cujas conclusões são complexas e influenciadas por uma série de fatores sociais, incluindo políticos, econômicos e éticos (SADLER, 2011). De relevância social, esse tipo de questão é frequentemente divulgado pela mídia, criando oportunidades para que todos os cidadãos, independentemente de sua profissão, interajam com a ciência (FRIEDRICHSEN et al., 2016).

Ressaltando a relevância social do problema, sua natureza controversa, e a multiplicidade de pontos de vista que esse tipo de questão envolve, Eastwood et. al. (2013) salientam o seu potencial para promover o interesse dos educandos em sala de aula de ciências, pois, além de incorporarem dados e os conteúdos "próprios" do espaço formal de ensino, oferecem aos estudantes a oportunidade de considerar os aspectos sociais, econômicos, morais vinculados ao problema.

No que diz respeito, portanto, à associação entre a integração de QSC na educação científica e sua importância para a formação de cidadãos alfabetizados cientificamente, Sadler e Zeidler (2009) destacam três princípios:

(1) A alfabetização científica deve ser o objetivo de todos os estudantes. A educação científica não deve ser reservada para aqueles poucos que estão destinados a ser tornar a próxima geração de cientistas, engenheiros e físicos. Dessa forma, a educação científica não deve focar exclusivamente em formalismos científicos que tenham relevância somente para os profissionais que praticam ciência. (2) A educação científica deve propiciar oportunidades para os aprendizes experimentaram a ciência em contextos análogos àqueles que eles confrontam em suas experiências diárias além dos muros escolares. (3) Quando educadores querem usar problemas reais relacionados à ciência, como veículo para engajar estudantes em experiências de aprendizagem significativas, eles não devem tentar destilar a ciência de forma a descartar outros elementos dos problemas que podem ser vistos como além dos limites da ciência tradicional. [...] essa abordagem "segura" vai contra o propósito de usar QSC como contextos para a aprendizagem (SADLER; ZEIDLER, 2009, p. 912, tradução nossa).

Com relação ao terceiro princípio, Bossér e Lindahl (2017) enfatizam algumas das dificuldades encontradas pelos professores ao lidarem com QSC. Segundo os autores, práticas dialógicas estabelecidas a partir de questões socialmente controversas exigem novas demandas para os professores, como propiciar um ambiente que encoraja os educandos a expressarem suas opiniões durante as discussões. Contudo, de acordo com as características desse tipo de questão, podem emergir em sala de aula aspectos relacionados a emoções oriundas da empatia com outros indivíduos.

Dessa forma, desenvolver estratégias que possibilitem o trato de tais emoções se torna importante para os professores. No entanto, o que tem se verificado na literatura é a falta de confiança dos docentes para lidar com outros aspectos que possam emergir das discussões para além dos conteúdos científicos tradicionais. Assim sendo, por mais que os docentes demonstrem interesse na abordagem de QSC no ensino de ciências, estes optam por uma abordagem mais segura que se contrapõe aos próprios objetivos da atividade.

Para Zeidler e Keefer (2003), o ensino de ciências com foco na abordagem contextualizada do conhecimento científico promove uma espécie de alfabetização "sobre ciência" relacionada com situações às quais os educandos estão sujeitos a encontrar em suas vidas como cidadãos. Dessa forma, a inserção de QSC na educação científica conduziria ao que os autores denominam como "alfabetização científica funcional", cujos elementos estão sintetizados no esquema da Figura 1. 
Figura 1 - Componentes da alfabetização científica funcional.

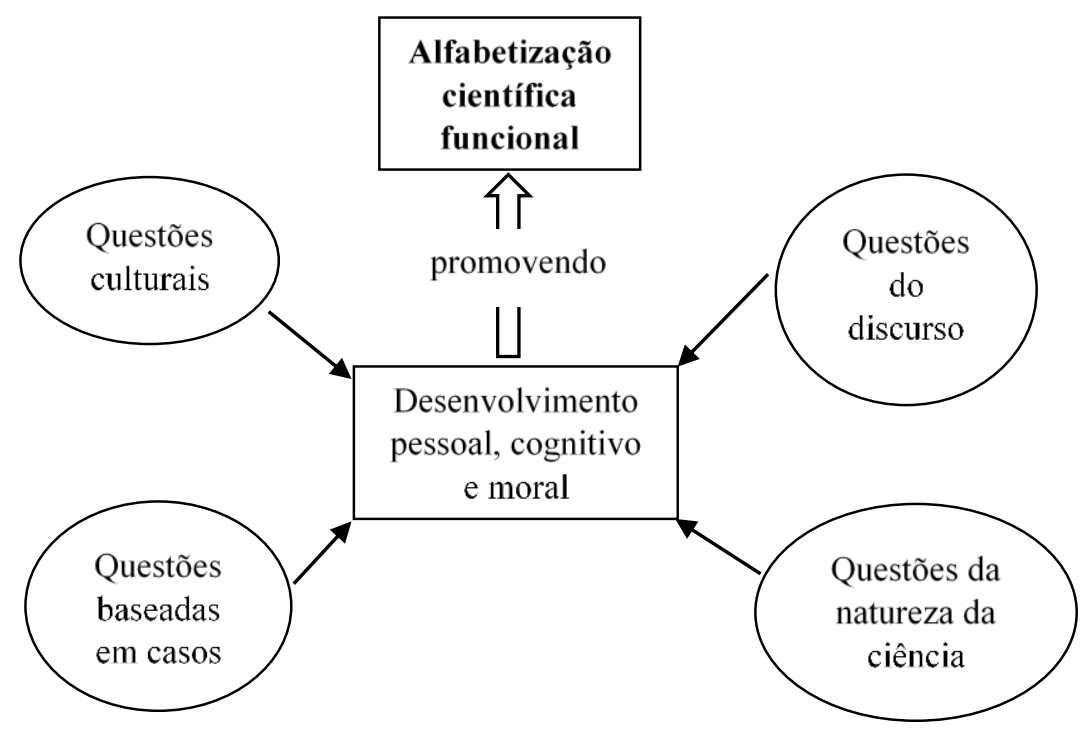

Fonte: Adaptado de Zeidler e Keefer (2003), tradução nossa.

Pelo esquema proposto por Zeidler e Keefer (2003), é possível inferir que cada um dos componentes contribui para o desenvolvimento pessoal, cognitivo e moral dos alunos, o que, por sua vez, promove essa alfabetização científica funcional. Conforme sugerido por Eastwood et. al. (2013), ambientes de aprendizagem baseados em QSC devem encorajar a participação dos estudantes, a colaboração e o respeito mútuo. Além disso, os educandos devem ter oportunidades de se engajarem em processos argumentativos, interagir com ideias científicas, dados reais, e negociar os aspectos sociais do problema. Dessa forma, as questões do discurso se apresentam na construção de argumentos, seus mecanismos, e como respostas e pontos de vista diante de problemas morais são afetados por crenças e convicções prévias.

Com relação às questões da natureza da ciência $(\mathrm{NdC})$, estas se tornam relevantes, pois podem revelar como as visões epistemológicas influenciam a seleção e a avaliação das evidências pelos estudantes, e assim afetar a construção de novos argumentos. As questões culturais se relacionam com a necessidade do respeito mútuo e tolerância a opiniões divergentes. E, por fim, questões baseadas em casos se tornam pertinentes, uma vez que, permitem aos educadores irem além do currículo CTS e cultivar hábitos que promovam a sensibilidade ética e moral (ZEIDLER, et. al., 2005).

Considerando os componentes apresentados por Zeidler e Keefer (2003) (Figura 1), no que diz respeito à alfabetização científica funcional, há pesquisas endereçadas para cada um deles. De particular interesse em nosso estudo, o item que os autores denominam como questões baseadas em casos, as quais se referem a situações que permitam promover a sensibilidade moral para ouvir vozes dissidentes e analisar como o poder de autoridade está incorporado na atividade científica, consiste em um componente da alfabetização científica funcional que ressalta uma das principais diferenças entre o ensino com ênfase CTS, e aquele tomado a partir da abordagem de QSC (Zeidler et. al. 2005).

Para Zeidler et al. (2005), apesar dos avanços oriundos de estudos fundamentados na educação CTS, como, por exemplo, apresentar e convencer a comunidade educacional que a ciência, a tecnologia e a sociedade não estão isoladas umas das outras, ela não 
considera abertamente os fundamentos epistemológicos, o desenvolvimento moral e ético, e os aspectos emocionais do aprendizado científico.

Dessa forma, a abordagem de QSC representa uma reconstrução da CTS, que fornece meios para o contato dos educandos com implicações do desenvolvimento científico e também para explorar os sistemas de crenças dos alunos. Para Zeidler et. al. (2005), portanto:

\begin{abstract}
Enquanto a educação CTS tipicamente salienta o impacto das decisões em ciência e tecnologia na sociedade, ela não impõe uma atenção explícita às questões éticas contidas nas escolhas sobre meios e fins, nem considera o desenvolvimento moral ou o caráter dos estudantes. [...]

Por adicionar o desenvolvimento moral, ético, emocional e epistemológico do estudante, a abordagem QSC fornece um elo que une as várias forças que contribuem para o desenvolvimento do conhecimento científico. A introdução de casos baseados em QSC representa uma estratégia pedagógica direcionada não somente para as ramificações sociológicas, como também para as ramificações psicológicas do currículo e do discurso em sala de aula (ZEIDLER et. al., 2005, p. 359 e 371, tradução nossa).
\end{abstract}

Diante dessa característica que diferencia o ensino baseado em QSC da abordagem CTS, aspectos morais são particularmente relevantes para a formação e o desenvolvimento de caráter e valores de cidadãos globais (LEE et. al., 2012). E, ainda, com relação às questões políticas e econômicas do contexto brasileiro atual, a abordagem desses aspectos na educação formal se torna imprescindível aos estudantes.

Configurando-se como uma temática transversal, a abordagem da ética se torna pertinente às diferentes áreas do saber, e envolve o acesso ao conhecimento e à capacidade de, a partir dele, o aluno tomar decisões e agir em serviço e a favor da comunidade. No entanto, para a tomada de decisão e a participação socialmente ativa, o indivíduo deve ser capaz de agir moralmente e assim utilizar valores considerados universalmente como norteadores das relações sociais e da conduta dos homens.

Nessa perspectiva, é interessante, inicialmente, estabelecer uma distinção entre moral e ética. Dentre a variedade de definições existentes na literatura, compartilhamos a visão de La Taille (2006), que considera a moral referente à dimensão dos deveres, isto é, com ela, buscamos responder "como devo agir?" ou "o que devo fazer?", e a ética uma reflexão filosófica ou científica sobre a moral. Assim, fazendo uso das palavras de Guimarães (2011, p. 7), “o dever de não mentir pertence à dimensão moral, mas a reflexão sobre se algumas vezes a mentira pode ser melhor ou menos danosa que a verdade, pertence à dimensão da ética". De modo geral, a moral é externa ao indivíduo e varia de acordo com a sociedade e a cultura em que ele está imerso.

Assim sendo, a moral estabelecida a partir dessa relação é descrita por Kant (2005) como uma moral heterônoma, a qual é guiada por motivos extrínsecos à pessoa. Nesse caso, conforme afirma Guimarães (2011), o indivíduo não enxerga o valor das regras em si, mas sim o valor que a sociedade atribui a elas.

Esse aspecto ressalta a importância da abordagem de questões que envolvam dimensões morais nos espaços formais de ensino. Segundo Bebeau et al. (1995), o indivíduo é treinado desde pequeno a seguir regras sem uma reflexão crítica do porquê delas; dessa forma, quando nos deparamos com situações que não possuem regras estabelecidas a priori encontramos dificuldades na tomada de decisão, ainda mais quando esta envolve o bem-estar de outras pessoas. 
Em contraposição a esta moral heterônoma, Kant (2005) propõe uma moral autônoma como ideal a ser alcançado, a qual também consiste no objetivo da educação voltada para essa questão. Nesse caso, fundamentada na razão e não na coerção social, as decisões e ações se originam do interior dos sujeitos.

A partir do que foi apresentado até o momento, emerge da literatura a vasta gama de possibilidades que QSC, comuns ao educando face à sua veiculação pela mídia, assumem no espaço formal de ensino de ciências, seja para abordagem de conteúdos científicos, ou para a compreensão de aspectos de $\mathrm{NdC}$. No entanto, de particular relevância para o trabalho aqui empreendido, observa-se também as contribuições desse tipo de abordagem não somente para o desenvolvimento de habilidades argumentativas e de tomada de decisão dos indivíduos, como também para o desenvolvimento moral dos educandos, em especial para a sensibilidade moral dos mesmos. Ademais, esses elementos e características das QSC propiciam um contexto adequado para que o objetivo principal da educação científica seja alcançado, isto é, para o que Zeidler e Keefer (2003) denominam como alfabetização científica funcional.

Este trabalho tem como objetivo investigar a sensibilidade moral de licenciandos em química, a partir do uso de QSC e, consequentemente, dos aspectos morais evidenciados pelos educandos em suas respostas a esse tipo de questão. Assim, também pretendemos apresentar um caminho para a abordagem de questões que envolvem dimensões morais em sala de aula. O emprego de QSC no âmbito de formação inicial de professores de química, vai ao encontro das colocações de Bossér e Lindahl (2017), os quais salientam a necessária implementação de práticas dessa natureza na formação de professores de modo que estes venham a atender as demandas oriundas de práticas dialógicas estabelecidas a partir de questões socialmente controversas em sala de aula.

\section{Fundamentação teórica}

Ao considerarmos a importância de estudos voltados para o desenvolvimento moral dos educandos, nos deparamos com diferentes modelos e teorias, dentre os quais o Modelo dos Quatro Componentes (REST; BEBEAU; VOLKER, 1986). Este, associado ao nosso interesse de promover práticas que contribuam para o desenvolvimento de uma moral autônoma (KANT, 2005), subsidiará nossas análises a respeito do grau de fundamentação moral das respostas empregadas pelos licenciandos quando diante de QSC.

De acordo com Bebeau, Rest e Narvaez (1999), o referido Modelo foi proposto como forma de sobrepor o obstáculo que impede a realização de pesquisas sólidas envolvendo a educação moral. Esse obstáculo é o que os autores chamam de visão tripartida da moral, na qual assume-se como elementos básicos da moralidade o afeto, a cognição e o comportamento, isto é, motivação (consideração pelos outros), habilidade (autorregulação) e identidade (identidade moral) (COHEN; MORSE, 2014).

Nessa perspectiva, o Modelo dos Quatro Componentes surge na tentativa de incorporar diferentes teorias para defender uma concepção mais ampla do funcionamento moral, lidar com uma série de problemas conceituais, como as relações entre cognição, afeto e comportamento, inerentes à visão tripartida da moral, e fornecer uma estrutura para a implementação e a avaliação de intervenções morais (WALKER, 2002). Esse Modelo sugere que a moralidade é construída com base em quatro componentes: a sensibilidade moral, o julgamento moral, o comprometimento moral e o caráter moral/perseverança moral. 
A sensibilidade moral diz respeito à capacidade de interpretação da situação. É a partir dela que o sujeito, em sintonia com as reações dos outros, cria cenários, por meio de pistas limitadas e informações parciais, que o permite tomar conhecimento dos possíveis cursos de ações para situação. É por meio dessa sensibilidade que o sujeito deve ser capaz de reconhecer os pontos de conflito, as possíveis ações, antecipar como cada uma delas poderia afetar o bem-estar das partes interessadas, e ainda, quem, incluindo a si mesmo, poderia ser afetado por essas ações.

O julgamento moral envolve uma deliberação à respeito das várias considerações relevantes para os diferentes cursos de ações, identificando a moralmente justificável, isto é, conhecendo as várias ações possíveis, a partir do julgamento moral o indivíduo deve ser capaz de avaliar qual ação é moralmente correta e qual é errada. O comprometimento moral diz respeito ao ato de, na tomada de decisão, o indivíduo priorizar valores morais acima de outros valores pessoais e se comprometer com o curso de ações, se responsabilizando pelos possíveis resultados. Por fim, o caráter moral se relaciona com a força das convicções, coragem, persistência em superar distrações e obstáculos. Envolve habilidades e estratégias de implementação que suportam a decisão tomada no âmbito do julgamento moral.

Apesar de se complementarem de certa forma, um processo pode ocorrer independentemente do outro, por exemplo, uma pessoa pode ser capaz de reconhecer as dimensões éticas de uma situação (sensibilidade moral), mas não ter a habilidade de traçar um plano de ações ou apresentar uma resposta bem fundamentada para o julgamento moral. Dessa forma, Rest, Bebeau e Volker (1986) salientam que uma falha moral pode ser devida a uma deficiência em qualquer um desses quatro componentes. E, é nessa possibilidade de entender as razões de uma falha moral que se encontra, para Bebeau, Rest e Narvaez (1999), o valor do Modelo dos Quatro Componentes, o qual permite ao educador desenvolver estratégias mais efetivas e ao pesquisador estabelecer variáveis de investigação.

Neste artigo, empregamos o referido Modelo para análise, principalmente, da sensibilidade moral. O foco neste item do Modelo dos Quatro Componentes encontra subsídios nas ideias de Fowler, Zeidler e Sadler (2009): a necessidade de maior conhecimento sobre a sensibilidade moral para pesquisas envolvendo o desenvolvimento moral parte do pressuposto que se o raciocínio moral é usado para determinar o curso de uma ação, então uma das primeiras necessidades desse processo consiste na habilidade de reconhecer os aspectos morais da situação.

A respeito da investigação dessa sensibilidade, fizemos uso do material elaborado por Bebeau et al. (1995), intitulado Moral Reasoning in Scientific Research. Nessa obra, os autores apresentam um compilado de casos que envolvem dimensões morais e que exigem a tomada de decisão dos alunos. Para cada caso é fornecido também uma grelha que permite ao professor a análise das respostas dos alunos e da respectiva sensibilidade moral.

Tais grelhas contêm o que para os autores seriam os aspectos morais envolvidos na situação, isto é, uma lista das partes direta ou indiretamente envolvidas, as quais podem ser afetadas pelas ações possíveis. Também são descritas as consequências de cada uma dessas ações, as obrigações daquele responsável por tomar a decisão, ou seja, do protagonista do caso e, por fim, a apresentação dos pontos de conflito presentes na situação narrada. Nesse contexto, um indivíduo com maior sensibilidade moral seria aquele que apresentasse em sua resposta um maior número de elementos sugeridos pelo autor. 
De forma semelhante ao proposto por Bebeau et al. (1995), a análise da sensibilidade moral neste estudo se deu por meio da adaptação, por parte dos autores deste artigo, de um caso extraído de um texto quadrinizado e da elaboração da sua respectiva grelha de aspectos morais pertinentes à situação narrada. Portanto, tal grelha se configura como principal instrumento de análise dos argumentos escritos no que diz respeito à sensibilidade moral dos licenciandos. Assim, consideramos que a quantidade de elementos morais presentes nas respostas dos futuros professores está diretamente relacionada com a sensibilidade moral dos mesmos.

\section{Contexto de aplicação da proposta}

O presente estudo foi realizado com sete alunos matriculados na disciplina Química, Sociedade e Cotidiano de Curso de Licenciatura em Ciências Exatas, modalidade Química de uma universidade pública do estado de São Paulo. Neste texto, os licenciandos são indicados por nomes fictícios, a saber: Alice, Bianca, Caroline, Débora, Érica, Francisco e Gabriel. Previamente à aplicação de qualquer atividade, uma apresentação do estudo foi realizada para os futuros professores, os quais, cientes da proposta, assinaram Termo de Consentimento Livre e Esclarecido para a participação na pesquisa.

A disciplina em questão é ofertada no período noturno, com encontros semanais de duração de 120 minutos. Além disso, ela está presente no último semestre do curso e tem como objetivo criar oportunidades para o desenvolvimento da capacidade de investigação e análise crítica dos alunos por meio de conhecimento, discussão, e posicionamento diante de problemas relacionados ao impacto da química na sociedade. Dessa forma, identificamos de antemão a pertinência da disciplina para uma abordagem com ênfase CTS, em especial para o emprego de QSC.

Como evidenciado anteriormente, para a promoção da argumentação diante de QSC que envolvessem dilemas éticos em contexto de formação inicial de professores de química, tomamos como base o material intitulado Moral Reasoning in Scientific Research. Este consiste em um material desenvolvido para o projeto denominado Teaching Research Ethics: A Workshop at Indiana University, e fornece subsídios para o exercício, em sala de aula de ciências, do raciocínio baseado em valores por meio de casos que envolvem dimensões morais.

No material em questão, Bebeau (1995) et al. apresentam seis casos que seguem todos um mesmo formato, isto é, narram uma situação na qual são apresentadas diversas informações ao leitor e que culmina em um dilema para o protagonista do caso. Assim, diante do conflito, o personagem narrado toma uma decisão. Então, é perguntado ao leitor se este deve prosseguir com o seu plano/sua decisão ou não, em ambos os casos deve ser evidenciada a justificativa. $\mathrm{O}$ interessante desse formato é que a decisão já está tomada, e cabe ao educando concordar ou não, forçando-o a argumentar e não simplesmente apresentar uma solução, que desconsiderando os aspectos morais seria considerada melhor na sua visão.

Além de apresentar os seis casos, Bebeau et al. (1995) descrevem os passos a adotar em sala de aula para a sua abordagem, bem como fornecem uma grelha com os aspectos morais de cada caso. Nessa perspectiva, os autores auxiliam no estabelecimento das discussões em sala de aula, e indicam os elementos que, quando considerados, conduzem a uma resposta bem fundamentada moralmente. A sequência sugerida para que seja seguida pelo professor a partir desses casos é: leitura e resolução individual inicial ao caso; 
discussão oral conduzida pelo docente acerca das respostas apresentadas inicialmente, de modo a vislumbrar coletivamente os aspectos morais inerentes à situação narrada; nova resposta individual ao caso com base nos aspectos levantados no momento de discussão.

Portanto, a partir desse material e da estrutura dos casos apresentados por Bebeau et al. (1995), desenvolvemos a partir da leitura da obra quadrinizada "Trinity: a história em quadrinhos da primeira bomba atômica" (FETTER-VORM, 2013), três casos que promovessem a argumentação diante de QSC. Aqui discutimos a respeito dos dados obtidos a partir da resolução de apenas um desses casos. Ressaltamos que no contexto da disciplina houve a leitura integral da referida história em quadrinhos (HQ) por parte dos licenciandos.

O emprego de HQ no ensino de ciências encontra subsídios nas ideias de diferentes autores que sugerem o potencial pedagógico destas, mediante características desse tipo de texto como a ludicidade e a linguagem. Outrossim, a HQ selecionada se mostra adequada para o atendimento do objetivo proposto com este estudo, uma vez que, apresentando como temática a construção das armas atômicas que culminaram na destruição de duas cidades japonesas em meio a Segunda Guerra Mundial, é abordado na HQ, de forma histórica, conceitual e polêmica, tópicos localizados na fronteira com a química e tópicos classificados como temáticas transversais interessantes para a promoção da argumentação. Essas temáticas transversais permeiam todo o currículo de formação do educando e no caso específico diz respeito à ética, principalmente na prática científica.

Extraídos os casos da HQ com base no material de Bebeau et al. (1995), também construímos grelhas que fornecessem subsídios para a identificação de uma resposta bem fundamentada moralmente. Essas grelhas apresentam as partes interessadas em cada conflito, as quais seriam diretas ou indiretamente afetadas pela decisão do(s) protagonista(s); as consequências de cada uma das ações; as obrigações daquele(s) responsável(is) pela tomada de decisão. Também apresentamos, nas grelhas, o ponto ou pontos de conflito presentes em cada caso. As grelhas, além de permitirem a análise da sensibilidade moral dos futuros professores, foram fundamentais para a condução das discussões em sala de aula.

Toda a atividade foi audiogravada, e as gravações das discussões, bem como os argumentos fornecidos pelos licenciandos antes e após o momento de reflexão conduzido pelo professor, consistem nos dados tomados para análise. Para além das gravações em áudio das discussões, analisamos os catorze argumentos escritos empregados pelos alunos, ou seja, as respostas iniciais e finais de cada um dos sete futuros professores matriculados na disciplina. Contudo, para efeito de discussão e respeitando o espaço disponível para este texto, conforme mencionado anteriormente, apresentamos a análise sistemática somente dos dados relacionados a uma das licenciandas, Alice, e ao final tecemos considerações a respeito de todos os argumentos obtidos a partir da aplicação do caso em sala de aula.

O caso adaptado e empregado para estudo encontra-se no Quadro 1. A sua leitura permite que se identifique um conflito envolvendo Oppenheimer e sua relação com os cientistas mediante as condições de trabalho dos mesmos e a necessidade de sigilo exigida pelo Projeto Manhattan. Essa situação implicava em um dilema para Oppenheimer, que deveria decidir entre deixar os cientistas livres para falar o que quisessem, mas somente dentro do laboratório, ficando por conta de cada um deles o policiamento a si mesmo, ou manter a obrigatoriedade do sigilo, mesmo que isso custasse a insatisfação dos pesquisadores e, consequentemente, um possível insucesso. O conflito do cientista é 
ampliado quando consideramos a dimensão militar do projeto, encabeçada pelo General Groves, o que resulta em diversas outras obrigações para Oppenheimer, conforme discutiremos na sequência.

Quadro 1 - Caso adaptado da HQ Trinity: a história em quadrinhos da primeira bomba atômica.

A questão do sigilo no Projeto Manhattan

O Projeto Manhattan, concebido por Groves, era impressionante por muitos motivos. Sua larga escala: a unidade de difusão, em Oak Ridge, no Tennessee, era o maior prédio do mundo. O número total de pessoas envolvidas: no auge da produção, cerca de 80 mil trabalhavam em Oak Ridge. O tempo espantosamente curto entre a prancheta e a linha de montagem: equipes de operários, trabalhando contra o relógio, terminavam uma nova casa a cada 15 minutos.

Mas outro fato impressionante pode facilmente passar desapercebido - todos esses esforços - esses milhares de trabalhadores, as incontáveis toneladas de material de construção e o imensurável investimento de tempo e energia - eram segredo. O povo americano - incluindo o Congresso - nem sequer sabia que o Projeto Manhattan existia.

[Senador] E como essa verba solicitada será exatamente aplicada? [Membro do Projeto Manhattan]. Isso é confidencial, senador.

Groves compartimentou o Projeto Manhattan de modo que nenhuma organização ou indivíduo tivesse completa noção daquilo em que estava trabalhando.

[Operário] Cuido para que os canos não vazem.

[Operária] Faço com que as máquinas não esquentem demais.

[Militar] Lembro as pessoas de não fazerem perguntas.

O Projeto Manhattan foi tão eficiente em manter sua confidencialidade que, mais tarde, organizações secretas como a CIA o usaram como modelo. Mas em Los Alamos - o novo lar de algumas das mentes mais brilhantes do país - a questão do sigilo não era assim tão simples.

[Cientistas] Não venha me falar de sigilo! Não há como fazer ciência sem a livre troca de ideias.

Um dos primeiros desafios de Groves foi tentar separar os cientistas: muitos deles se recusaram totalmente a fazer isso.

[Militar] Eles ignoram suas ordens, senhor! O que devo fazer?

[Groves] São um bando de crianças. Eles só precisam de um pouco de disciplina.

[Oppenheimer] Você sabe que a maioria desses homens deixou a Europa para fugir do militarismo

[Groves] Mas é como se eles nem entendessem que estamos em guerra.

[Oppenheimer] Mas você não acha que eles têm razão? Como você espera que eles colaborem entre si se não sabem o que os outros estão fazendo? E se os cientistas fossem livres para falar o que quisessem ..., mas só dentro do laboratório? Todos podem saber tudo, mas somente numa área cuidadosamente restrita. E fica por conta dos cientistas policiarem a si mesmos?

Nessa situação, deveria Oppenheimer seguir com o plano de deixar os cientistas livres para falar o que quisessem, mas só dentro do laboratório, ficando por conta de cada um deles o policiamento a si mesmo? Sim ou não? Por quê?

Fonte: Fetter-Vorm, 2013, p. 33 - 36.

De acordo com o que é narrado no caso, apresentamos no Quadro 2 a grelha de aspectos morais envolvidos nessa tomada de decisão de Oppenheimer. Conforme podemos observar, destacamos como partes interessadas pela situação narrada, o protagonista do caso, isto é, Oppenheimer, e os indivíduos cujo trabalho seria diretamente afetado pela decisão, os cientistas. Além disso, mediante acordo firmado inicialmente entre Oppenheimer, Groves e o governo norte-americano, são também estes dois últimos, partes envolvidas na tomada de decisão. Ademais, os governos rivais interessados na construção de um artefato nuclear e toda a população norte-americana se configuram como entidades que podem ser afetadas pelas consequências da ação tomada por Oppenheimer.

Por falar em consequências, destacamos algumas, como: a maior possibilidade de vazamento de informações a respeito do Projeto Manhattan, caso seja concedida 
determinada liberdade para os cientistas se comunicarem dentro dos laboratórios de Los Alamos; e a execução do projeto de forma mais rápida e a contento, face à condição de trabalho ideal para os cientistas oriunda do trabalho em equipe.

Contudo, são também possíveis implicações inerentes à situação narrada: um ambiente de pressão que dificulta a prática científica e um mau comportamento dos cientistas caso sua demanda não fosse atendida, o que por sua vez conduzem a um maior tempo necessário para a finalização do projeto e um prolongamento da guerra. Ainda, ao considerarmos Oppenheimer como o protagonista da situação, salientamos algumas de suas obrigações que influenciam a sua tomada de decisão, isto é, o seu dever de, enquanto cientista, respeitar a natureza da ciência; conhecedor dos diversos aspectos envolvendo o projeto, de assegurar um bom trabalho para os cientistas. Em contrapartida, diante do componente militar do projeto, deve Oppenheimer manter o acordo de sigilo assumido previamente, evitando o vazamento de informações e respondendo a Groves e ao governo norte-americano.

Quadro 2 - Grelha de aspectos morais para o caso empregado em sala de aula.

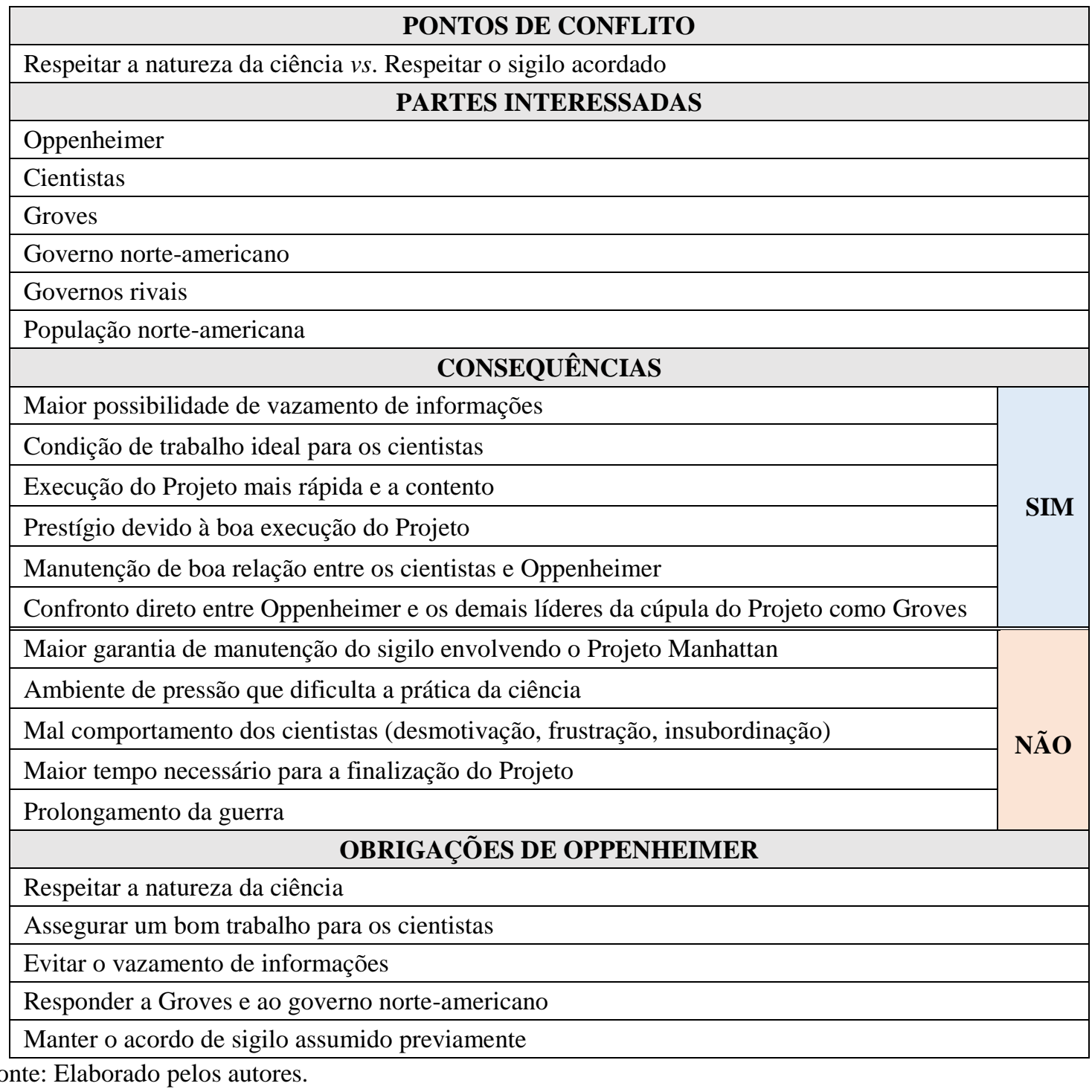




\section{Resultados e discussão}

Como mencionado, para efeito de discussão, apresentaremos na sequência uma análise sistemática das respostas empregadas pela licencianda Alice de modo a identificarmos a fundamentação moral das mesmas. Posteriormente, teceremos considerações globais a respeito de todos os argumentos fornecidos pelos futuros professores. Assim sendo, com base nos aspectos morais presentes na grelha que se encontra no Quadro 2, esquematizamos no Quadro 3 a resposta inicial da licencianda.

Quadro 3 - Análise da sensibilidade moral de Alice, de acordo com a resposta inicial ao caso

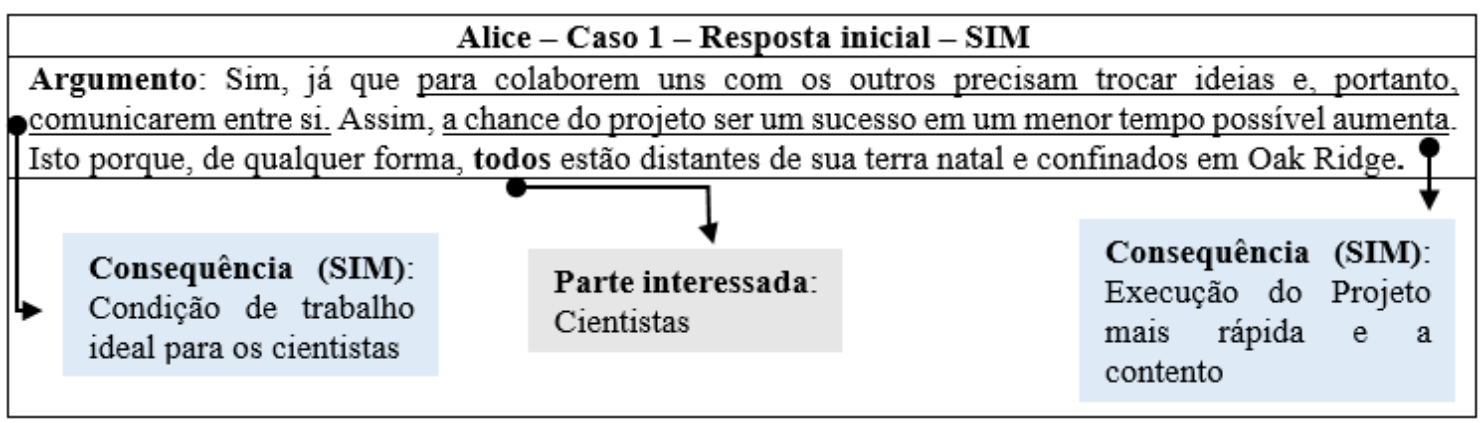

Fonte: Elaborado pelos autores.

Diante do que é apresentado no Quadro 3, podemos constatar uma sensibilidade moral bastante limitada da licencianda. Apresentando apenas uma única justificativa para sustentar seu posicionamento inicial, o qual é favorável à decisão de Oppenheimer, Alice omite o protagonista em sua resposta, e considera apenas duas consequências do posicionamento assumido. Além disso, dado que a decisão envolve o trabalho dos cientistas, estes são para Alice, conforme observado em sua resposta, parte exclusiva interessada nesse conflito.

Constatamos a ausência de qualquer obrigação de Oppenheimer, uma vez que na resposta da licencianda identificamos apenas os cientistas como parte interessada na situação. Dessa forma, ausentes as obrigações do protagonista, tais quais respeitar a natureza da ciência e manter o sigilo acordado inicialmente, o ponto de conflito que elencamos para o caso narrado não foi abordado pela aluna (Quadro 2).

A respeito da sensibilidade moral, portanto, considerando valores absolutos, dos 23 aspectos que destacamos como relevantes para a situação narrada e que constam na grelha presente no Quadro 2, apenas três são mencionados pela licencianda, o que representa aproximadamente 13\%. Destes, há o predomínio de consequências exclusivas para a posição tomada. Para a licencianda em questão, verificamos uma limitada sensibilidade moral a qual é corroborada pela literatura. De fato, Bebeau et al. (1995), por exemplo, salientam que muitos estudantes têm dificuldades em vislumbrar todos os pontos de disputa e discussão em um conflito ético.

A partir da primeira resposta, uma discussão oral foi conduzida pelo docente de modo que os licenciandos fossem capazes de vislumbrar com maior amplitude os aspectos morais pertinentes ao caso. Apresentamos, no Quadro 4, a análise da sensibilidade moral da licencianda Alice com base em sua segunda resposta ao caso.

Quadro 4 - Análise da sensibilidade moral de Alice, de acordo com a resposta final ao caso. 


\begin{tabular}{|c|c|c|c|c|}
\hline \multicolumn{5}{|c|}{ Alice - Caso 1 - Resposta final - NÃO } \\
\hline \multicolumn{5}{|c|}{$\begin{array}{l}\text { Argumento: Oppenheimer sabe que para a ciência se desenvolver melhor necessita de colaboração } \\
\text { mas quando entrou no Projeto Manhattan aceitou um acordo com Groves de manter o sigilo total sobre } \\
\text { este projeto, de modo que ele tem a obrigação de articular as ideias dos cientistas por conhecer o projeto } \\
\text { na totalidade, mas não permitir que os cientistas o saibam também. Por isso, apesar das grandes } \\
\text { dificuldades que ele deverá enfrentar com os cientistas, motivando-os constantemente e evitando } \\
\text { insubordinação, ele não deve permitir trocas de informações dentro dos laboratórios por uma questão de } \\
\text { ética e compromisso firmado incialmente com Groves e consequentemente com o governo norte- } \\
\text { americano. }\end{array}$} \\
\hline \multirow{2}{*}{\multicolumn{2}{|c|}{$\begin{array}{l}\text { Consequência (NÃO): } \\
\text { Mal comportamento dos } \\
\text { cientistas (desmotivação, } \\
\text { frustração, insubordinação) }\end{array}$}} & \multicolumn{3}{|c|}{$\begin{array}{l}\text { Ponto de conflito: Respeitar a natureza da ciência Vs. } \\
\text { Respeitar o sigilo acordado }\end{array}$} \\
\hline & & \multirow{2}{*}{\multicolumn{2}{|c|}{$\begin{array}{l}\text { Obrigação de Oppenheimer: } \\
\text { Evitar o vazamento de } \\
\text { informações }\end{array}$}} & Obrigação de \\
\hline \multicolumn{2}{|c|}{$\begin{array}{l}\text { Obrigação de Oppenheimer: } \\
\text { Assegurar um bom trabalho } \\
\text { para os cientistas }\end{array}$} & & & $\begin{array}{l}\text { Oppenheimer: } \\
\text { Manter o acordo de } \\
\text { sigilo assumido } \\
\text { previamente }\end{array}$ \\
\hline $\begin{array}{l}\text { Parte interessada: } \\
\text { Governo norte- } \\
\text { americano }\end{array}$ & \multicolumn{2}{|c|}{$\begin{array}{l}\text { Parte interessada: } \\
\text { Cientistas }\end{array}$} & $\begin{array}{l}\text { Parte interessada: } \\
\text { Groves }\end{array}$ & $\begin{array}{l}\text { Parte interessada: } \\
\text { Oppenheimer }\end{array}$ \\
\hline
\end{tabular}

Fonte: Elaborado pelos autores.

A respeito do caso envolvendo o sigilo interno do Projeto Manhattan, a licencianda Alice optou por alterar seu posicionamento inicial: passou a defender em seu argumento que Oppenheimer não deveria seguir adiante com o seu plano de conceder liberdade para os cientistas falar o que quisessem, mesmo que somente dentro dos laboratórios. Para tanto, a licencianda faz uso em sua resposta de apenas uma única consequência, a qual diz respeito exclusivamente ao seu posicionamento tomado naquele momento. Uma vez que Alice se mostra contrária à decisão de Oppenheimer, a consequência exposta no argumento se refere a um produto deste posicionamento, o qual é um possível mau comportamento dos cientistas durante o desenvolvimento do Projeto Manhattan.

Prosseguindo em nossa análise, identificamos, na resposta de Alice, uma ampliação de sua sensibilidade moral comparativamente à resposta fornecida inicialmente, ou seja, identificamos no seu texto um maior número de aspectos morais pertinentes ao caso e que subsidiaram a resposta. Podemos assumir que essa ampliação está diretamente relacionada com a discussão estabelecida em sala de aula, a qual foi conduzida pelo docente conforme trecho a seguir.

[P]: Então a gente viu, na aula passada, que, para conseguirmos julgar uma questão ética ou moral, como a gente queira falar, a gente tem que ter alguns parâmetros que vão auxiliar a nossa discussão. O primeiro parâmetro que a gente olha, na verdade, é quem são as partes interessadas nessa situação. Então, quem são as partes interessadas nessa questão? De permitir ou não que o sigilo seja quebrado pelo menos dentro do laboratório? Porque a questão toda é o sigilo, vocês identificam isso, certo? Então quem são as partes interessadas nessa questão?

A partir da discussão que se iniciou com a fala acima citada do professor formador, identificamos na resposta final da licencianda quatro partes interessadas, isto é, aproximadamente 67\% daquelas presentes na grelha esquematizada no Quadro 2. Dentre as partes interessadas abordadas por Alice, destacamos a presença de Oppenheimer, o protagonista, o que conduziu a aluna a ponderar a respeito de suas obrigações. Dessa 
forma, se faz também presente no argumento da futura professora três obrigações do protagonista que foram negligenciadas inicialmente, ou seja, a obrigação de Oppenheimer, enquanto cientista, assegurar um bom ambiente de trabalho para os demais colegas, evitar o vazamento de informações e manter o acordo de sigilo assumido previamente.

Nessa perspectiva, com base nas obrigações do protagonista, Alice inicia sua resposta com uma sistematização do conflito existente na decisão de Oppenheimer, o qual contrapõe duas de suas obrigações (assegurar um bom trabalho para os cientistas vs. manter o acordo assumido previamente com superiores). Portanto, o que se identifica no segundo texto da licencianda, elaborado após a discussão que permitiu os futuros professores contemplarem diferentes aspectos do caso narrado, é a indicação de alguns desses elementos em sua resposta, elementos estes que fortalecem, até certo ponto, o posicionamento de Alice.

Analisando valores absolutos, nesse segundo momento, Alice considera em sua resposta para o seu posicionamento nove dos 23 elementos expostos na grelha presente no Quadro 2, o que representa cerca de $39 \%$ dos aspectos julgados relevantes pelos pesquisadores, e denota um aumento da sensibilidade moral após a discussão estabelecida em sala de aula. Dentre os elementos abordados pela licencianda, o destaque se encontra nas menções das partes interessadas, as quais envolvem $\mathrm{o}$ protagonista, $\mathrm{e}$ consequentemente as obrigações deste. Porém, nas duas respostas de Alice, pouca atenção foi despendida para a análise das consequências das possíveis ações, principalmente daquelas contrárias ao posicionamento assumido, o que é reflexo do próprio enfoque dado pela futura professora em sua resposta.

Embora tenha apresentado posições contrárias, em ambos os argumentos de Alice identificamos o emprego de um enfoque que a literatura denomina deontológico (COSTA, 2002), em contraponto a um enfoque consequencialista. Segundo Costa (2002), neste enfoque, se configurando em uma moral demasiadamente simples e rígida, o centro do valor moral está nas regras morais, isto é, em preceitos universais da moralidade. Nessa perspectiva, centrando-se apenas na ideia de que na ciência os pesquisadores precisam colaborar entre si (preceito que diz respeito à natureza da ciência), Alice apresenta seu posicionamento inicial. No segundo momento, mantendo um enfoque mais deontológico em sua resposta, a futura professora se restringe à ideia/moral de que, ao assumir um acordo, no caso um acordo de sigilo, o indivíduo deve ir adiante com sua palavra.

Ao considerarmos a relação desses enfoques com os processos envolvidos na tomada de decisão diante de conflitos éticos, principalmente a sensibilidade moral, $\mathrm{o}$ enfoque deontológico assumido nas respostas vai ao encontro da moral heterônoma de Kant (2005), a qual permite a resolução de conflitos, sem a necessidade de uma sensibilidade moral mais acurada. Contudo, a partir do que é apresentado por Guimarães (2011), relembramos um dos principais problemas que podem surgir a partir dessa abordagem e dessa moral heterônoma, isto é, o relativismo moral. Segundo o autor, a partir do momento que a moral é de cada sociedade e o indivíduo age de acordo com ela, este pode observar atrocidades sendo cometidas em algumas sociedade e culturas, sem emitir qualquer condenação de juízo moral. Ainda, segundo Guimarães (2011, p. 8): "ser tolerante em relação às diferentes culturas não significa endossar atos reprováveis do ponto de vista moral".

Como sinalizado, todos os textos dos demais licenciandos foram analisados de modo a identificar a presença dos aspectos morais que consideramos relevante ao caso e 
que configuraria uma resposta bem fundamentada moralmente. Dessa forma, construímos, conforme ilustra a Figura 2, um gráfico que sumariza o grau de sensibilidade moral evidenciado por cada aluno em seus argumentos, isto é, a porcentagem de aspectos morais evidenciados nas diferentes respostas.

Figura 2 - Distribuição gráfica da combinação de elementos apresentados pelos licenciandos em seus argumentos.

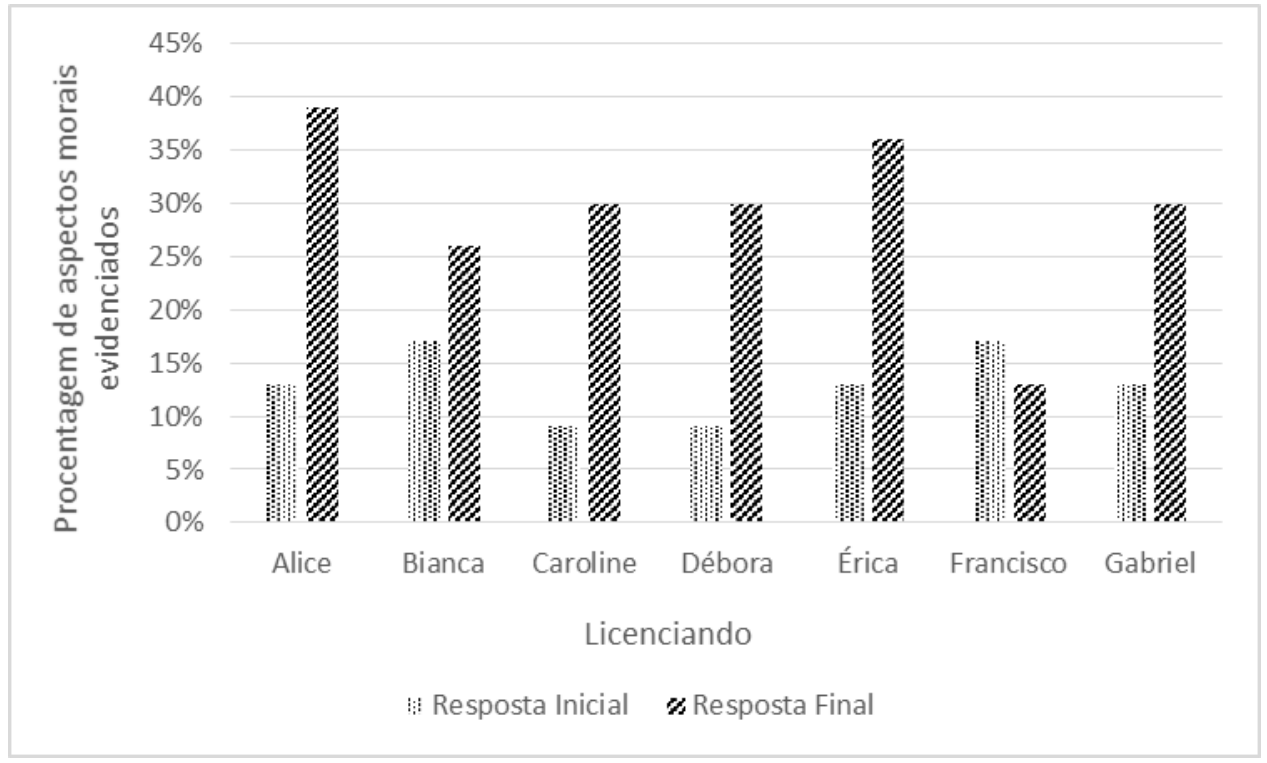

Fonte: Elaborado pelos autores.

Diante do que foi apresentado, constatamos uma limitada sensibilidade moral para todos os licenciandos, isto é, conforme podemos observar pela Figura 2, o texto que evidenciou maior sensibilidade moral foi aquele fornecido por Alice após a discussão, o qual conta com apenas 39\% dos aspectos morais que julgamos relevantes ao caso. Em sua maioria, essa baixa sensibilidade é resultado de enfoques maioritariamente deontológicos na perspectiva de Costa (2002), a qual está intimamente relacionada à moral heterônoma de Kant (2005).

Além disso, observamos, a partir dos resultados obtidos, a necessidade de mais práticas voltadas para o desenvolvimento moral dos educandos em sala de aula. No caso específico, no ensino superior, o que por sua vez não deixa de sinalizar lacunas no percurso formativo dos sujeitos em estudo com destaque para a educação básica. Outrossim, embora tenhamos observado essa limitada sensibilidade moral, com exceção de Francisco, os argumentos finais dos licenciandos sinalizam a contribuição da discussão estabelecida em sala de aula para uma ampliação da sensibilidade dos alunos.

A respeito dos diferentes elementos que configuram uma resposta bem fundamentada moralmente, de forma a compreender aqueles que conferem maior complexidade no que tange à determinação dos aspectos morais inerentes a um conflito ético, representamos graficamente, conforme ilustrado na Figura 3, a frequência de menções a cada um dos elementos considerados por Bebeau et al. (1995) como indicativos de uma resposta bem fundamentada moralmente.

Nesse sentido, o gráfico em questão exibe o percentual de elementos abordados nas respostas dos sete licenciandos antes e após a discussão conduzida em sala de aula, ou seja, 
a frequência de partes interessadas, de consequências, de obrigações do protagonista, e de pontos de conflito. Dessa forma, podemos inferir também quais aspectos foram mais influenciados pelo tipo de texto empregado em sala de aula, isto é, uma obra quadrinizada, e qual a extensão dos efeitos oriundos dos momentos de reflexão na construção das respostas finais dos licenciandos.

Figura 3 - Representação gráfica das frequências de menções às partes interessadas, às consequências, às obrigações do protagonista e aos pontos de conflito nas respostas dos licenciandos.

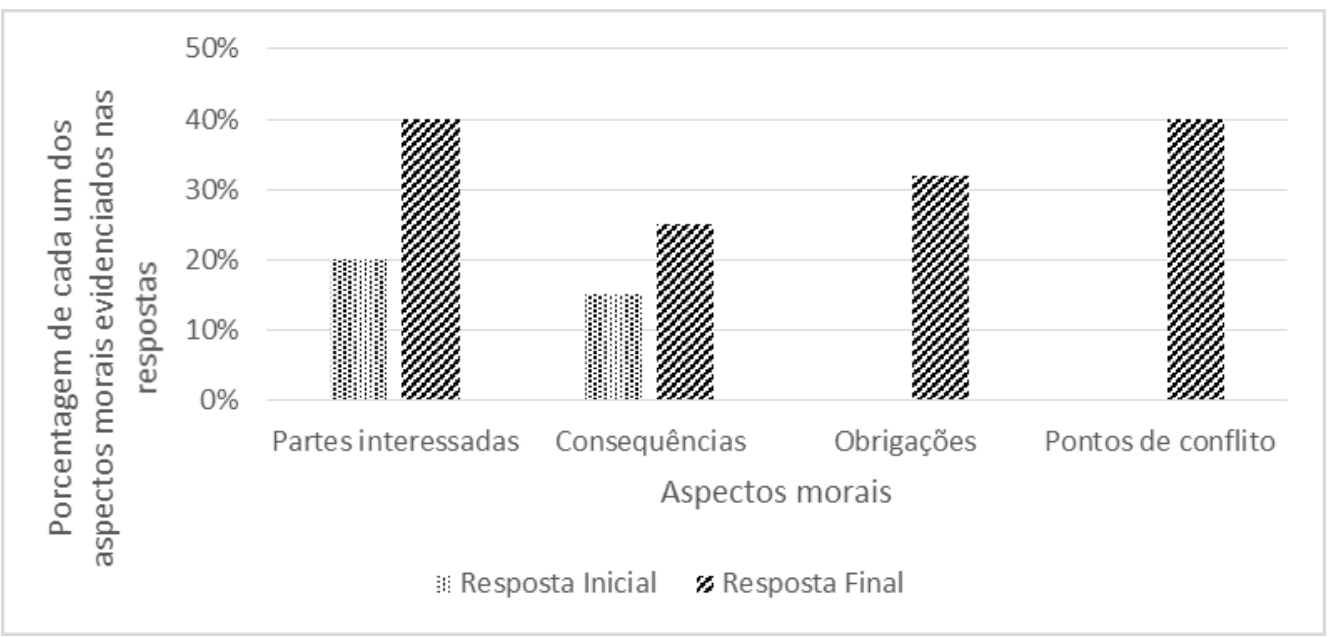

Fonte: Elaborado pelos autores.

Com base no que é apresentado graficamente, podemos observar um predomínio de menções às diferentes partes interessadas envolvidas. Essa constatação vai ao encontro das ideias de McCloud (2005), a respeito do hipergênero textual empregado em nossas atividades. Segundo o autor, grande parte do sucesso das HQ diz respeito à possibilidade de maior proximidade entre leitor e personagem promovido pela linguagem dos quadrinhos, a qual emprega textos verbais e imagens em, quase sempre, perfeita harmonia. Nessa perspectiva, diante da oportunidade de visualização dos diferentes personagens, que por meio também de uma série de recursos possíveis como uso o primeiro plano, são capazes de dialogar diretamente com o interlocutor, os futuros professores exibiram maior facilidade em mencioná-los em seus textos.

A partir da Figura 3, também é digno de nota a contribuição da sequência de atividades desenvolvidas para a sensibilidade moral, principalmente no que tange ao reconhecimento das obrigações dos protagonistas, o que pode futuramente levá-los a reconhecer com mais facilidade os pontos de conflito presentes em dilemas éticos. Nesse contexto, o que se verifica é a presença de menções a obrigações de Oppenheimer e, consequentemente, ao ponto de conflito após a discussão.

Com relação às consequências possíveis de cada decisão narrada, percebemos que o número de menções a elas apesar de significativamente maior, apresentou menor variação entre os diferentes momentos devido à presença majoritária do enfoque deontológico (COSTA, 2002) em algumas das respostas. Em contraste com um enfoque consequencialista, a ponderação de consequências sob uma ótica deontológica se torna irrelevante para a tomada de decisão. Portanto, o que se verifica, uma vez que entendemos como objetivo da educação moral a formação de indivíduos críticos que atendam à moral 
autônoma de Kant (2005), é a patente necessidade dessa temática transversal em sala de aula, nos mais variados níveis de instrução.

No mais, representando uma maior dificuldade de identificação pelos licenciandos, nenhum ponto de conflito foi mencionado nas respostas escritas iniciais dos alunos, sinalizando assim a principal lacuna no que diz respeito à sua sensibilidade moral. Porém, assim como houve um salto no que diz respeito à capacidade dos educandos em identificarem, direta ou indiretamente, as obrigações dos protagonistas, os resultados obtidos fornecem indício das possibilidades oriundas da atividade empregada em sala de aula para uma ampliação de faculdade de determinação dos pontos de conflitos. Assim, somos levados a crer que práticas como esta, realizadas de forma contínua, poderiam facilitar a identificação desse elemento, uma vez que, reconhecidas as obrigações morais daquele que toma a decisão nos diferentes conflitos, sua contraposição na maioria das vezes indicaria o conflito existente.

Por fim, mais uma vez são evidentes as contribuições e a influência das discussões conduzidas em sala de aula para a ampliação da sensibilidade moral dos indivíduos. Essa influência é nítida face o aumento do número de menções de cada um dos quatro elementos presentes na Figura 3 após a discussão. No mais, salientamos a importância desse momento não só para que os educandos possam vislumbrar aspectos elencados pelos colegas, mas para que possam ser capazes de apresentar suas ideias e opiniões.

Nessa perspectiva, concordamos com as afirmações de Bossér e Lindahl (2017) e enfatizamos a necessidade de práticas envolvendo o uso de QSC também na formação inicial de professores. Dessa forma, estes, em sua atividade docente futura, serão capazes de lidar com aspectos relacionados a emoções oriundas da empatia com outros indivíduos, e desenvolver estratégias que os auxilie no trato de tais emoções.

\section{CONSIDERAÇÕES FINAIS}

A partir da aplicação de um caso extraído de uma HQ, que consideramos abordar dilemas éticos, concluímos que embora futuros professores não apresentem elevada sensibilidade moral a princípio, as atividades didáticas realizadas a partir do texto quadrinizado, isto é, as discussões estabelecidas em sala de aula diante de questões que envolvem aspectos morais, contribuíram positivamente para o seu desenvolvimento. E, ainda que os resultados obtidos indiquem lacunas na formação dos educandos, vão ao encontro das considerações de Bebeau et al. (1995), os quais salientam a dificuldade da tomada de decisão diante de situações que não possuem regras estabelecidas a princípio.

Considerando ainda as colocações de Bebeau et al. (1995), observamos que as dificuldades naturalmente encontradas frente a dilemas éticos, são devidas essencialmente à moral predominante na sociedade moderna, isto é, a moral heterônoma de Kant (2005). Assim sendo, podemos identificar os efeitos dessa "moral vigente" nos argumentos e consequentemente na sensibilidade moral dos licenciados, quando em diferentes ocasiões constatamos o enfoque maioritariamente deontológico (COSTA, 2002) em suas respostas.

No que tange à metodologia proposta por Bebeau et al. (1995), a qual envolve três diferentes etapas de aplicação, ressaltamos a conveniência do momento de discussão estabelecido em sala de aula. Esse momento permitiu não somente que os licenciandos pudessem contemplar aspectos negligenciados em suas respostas iniciais, como também apresentassem suas ideias e opiniões. $\mathrm{O}$ ambiente propiciado pela reflexão conduzida pelo 
professor vai ao encontro das necessidades que derivam da abordagem de QSC em sala de aula, como a de fornecer um contexto que encoraja educandos a expressar suas concepções acerca da temática abordada. Ademais, essa discussão contribuiu significativamente para a ampliação da sensibilidade moral dos licenciados, conforme constatamos nas respostas finais fornecidas pelos mesmos para o caso.

Também podemos salientar, a partir da sua aplicação, a adequação e a relevância do Modelo dos Quatro Componentes (REST; BEBEAU; VOLKER, 1985), associado ao material instrucional elaborado por Bebeau et al. (1995), para estudos envolvendo o desenvolvimento moral dos educandos. Nessa perspectiva, com nosso trabalho, evidenciamos as potencialidades do Modelo para tratamento de um tópico que consideramos fundamental para a formação do cidadão atuante na sociedade moderna, sendo o ensino de ciências um ambiente favorável para a sua abordagem.

Assim sendo, o trabalho aqui realizado a partir desse Modelo permite a possibilidade de maiores reflexões a respeito de uma temática fundamental para a educação para cidadania, almejando a formação de indivíduos que exerçam a moral autônoma na perspectiva de Kant (2005). Em suma, as ações realizadas por meio deste trabalho se mostraram viáveis para o estudo aqui proposto e possibilitam diferentes abordagens e adaptações não somente para aplicação na formação de professores de ciências como também na educação básica.

\section{REFERÊNCIAS}

AULER, D. Novos caminhos para a educação CTS: ampliando a participação. In.: SANTOS, W.; AULER, D. (orgs.) CTS e educação científica: desafios, tendências e resultados de pesquisas. Brasília: Universidade de Brasília, 2011, p. 73-97.

BEBEAU, M. J. et al. Moral reasoning in scientific research: cases for teaching and assessment. Indiana University, 1995.

BEBEAU, M. J.; REST, J. R.; NARVAEZ, D. Beyond the promise: a perspective on research in moral education. Education Researcher, v. 28, n.4, p. 18 - 26, 1999.

BOSSÉR, U.; LINDAHL, M. Students' positioning in the classroom: a study of teacherstudent interactions in a sociocientific issu context. Research in Science Education, p. 1 20, 2017.

CACHAPUZ, A. et al. Do estado da arte da pesquisa em educação em ciências: linhas de pesquisa e o caso Ciência-Tecnologia-Sociedade. Alexandria: Revista de Educação em Ciência e Tecnologia, v. 1, n.1, p. 27-49, 2008.

COHEN, T. R.; MORSE, L. Moral character: what it is and what it does. In. BRIEF, A. P.; STAW, B. M. (Eds.). Research in Organizational Behavior. Elsevier, 2014.

COSTA, C. F. Razões para o utilitarismo: uma avaliação comparativa de pontos de vista éticos.ethic@ - Revista Internacional de Filosofia Moral, v. 1, n. 2, p. 155-174, 2002.

EASTWOOD, J. L. et al. Students' participation in an interdisciplinary, socioscientific issues based undergraduate human biology major and their understanding of scientific inquiry. Research in Science Education, v. 43, n.3, p. 1051 - 1078, 2013. 
FETTER-VORM, J. Trinity: a história em quadrinhos da primeira bomba atômica. São Paulo: Três Estrelas, 2013.

FOWLER, S. R.; ZEIDLER, D. L.; SADLER, T. D. Moral sensitivity in the context of socioscientific issues in high school science students. International Journal of Science Education, v. 31, n.2, p. 279 - 296, 2009.

FRIEDRICHSEN, P. J. et al. Design of a socio-scientific issue curriculum unit: antibiotic resistance, natural selection, and modeling. International Journal of Desings for Learning, v. 7, n.1, p. $1-18,2016$.

GUIMARÃES, M. A. Raciocínio informal e a discussão de questões sociocientíficas: o exemplo das células-tronco humanas. Tese (Doutorado em Educação para Ciência). Universidade Estadual Paulista, Bauru, 2011.

KANT, I. Fundamentação da metafísica dos costumes. Lisboa: Edições 70. 2005.

KARISAN, D.; ZEIDLER, D. L. Contextualization of nature of science whitin the socioscientific issues framework: a review of research. International Journal of Education in Mathematics, Science and Technology, v. 5, n.2, p. 139 - 151, 2017.

LA TAILlE, Y. Moral e ética: dimensões intelectuais e afetivas. Porto Alegre: Artmed, 2006.

LEE, H. et al. Developing character and values for global citizens: analysis of pre-service science teachers' moral reasoning on socioscientific issues. International Journal of Science Education, v. 34, n.6, p. 925 - 953, 2012.

MCCLOUD, S. Desvendando os quadrinhos: história, criação, desenho, animação, roteiro. São Paulo: M. Books, 2005.

PEDRETTI, E.; NAZIR, J. Currents in STSE Education: mapping a complex field, 40 years on. Science Education, v. 95,n.4, p. 601-626, 2011.

REST, J.R.; BEBEAU, M.J.; VOLKER, J. An overview of the psychology of morality. In REST, J. R. (Ed.) Moral development: Advances in research and theory. Boston: Prager Publishers. 1986.

ROEHRIG, S. A. G.; CAMARGO, S. A educação com enfoque CTS no quadro das tendências de pesquisa em ensino de ciências: algumas reflexões sobre o contexto brasileiro atual. Revista Brasileira de Ensino de Ciência e Tecnologia, v.6, n.2, p. 117-131, 2014.

SADLER, T. D. Informal reasoning regarding socioscientific issues: a critical review of research. Journal of Research in Science Teaching, v.41, n.5, p.513 - 536, 2004.

SADLER, T. D. (Ed.). Socioscientific issues in the classroom: teaching, learning, and research. New York: Springer, 2011.

SADLER, T. D.; ZEIDLER, D. L. Scientific literacy, PISA, and socioscientific discourse: Assessment for progressive aims of science education. Journal of Research in Science Teaching, v. 46, n.8, p. $909-921,2009$. 
STRIEDER, R. B.; KAWAMURA, M. R. D. Educação CTS: parâmetros e propósitos brasileiros. Alexandria: Revista de Educação em Ciência e Tecnologia, v. 10, n.1, p. 27$56,2017$.

WALKER, L. J. The model and the measure: an appraisal of the Minnesota approach to moral development. Journal of Moral Education, v. 31, n.3, p. 353 - 367, 2002.

ZEIDLER, D. L.; KEEFER, M. The role of moral reasoning and the status of socioscientific issues in science education: philosophical, psychological and pedagogical considerations. In. ZEIDLER, D. L. (Ed.). The role of moral reasoning on socioscientific issues and discourse in science education. Dordrecth: Kluwer Academic Press, 2003.

ZEIDLER, D. L. et al. Beyond STS: A research-based framework for socioscientific issues education. Science Education, v.89, n.3, p. 357 - 377, 2005.

Recebido em: 12/11/2018

Aprovado em: 06/01/2019 